\title{
MEDIA SCHEMAS, PERCEIVED EFFECTS, AND PERSON PERCEPTIONS
}

\author{
By Patrick C. Meirick
}

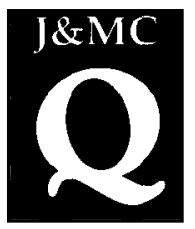

Media schemas about the power of the media are widely thought to influence perceived media effects and third-person perception, but only one study has shown this, and it did not consider desirable messages. The current research finds focus group evidence for the existence of additional media schemas relevant to estimating effects of pro-social messages, then examines the relationships between media schemas, perceived media effects of desirable and undesirable messages on self and others, and first-, second-, and third-person perceptions. Results indicate that some media schemas can be applied to perceived media effects of self and others, although not exclusively to desirable or undesirable messages. There was no evidence that these schemas are related to first- or third-person perception, but they seem to be better suited to predict the mutual perceived effects of second-person perception.

For almost as long as there have been mass media, there have been widespread conceptions about their power. ${ }^{1}$ When King Henry VIII took control of printing presses in England in 1529, he demonstrated the same kind of belief in the media's persuasive power that Davison saw in the white officers who withdrew their black troops after the troops had been targeted by Japanese leaflets in World War II. ${ }^{2}$ It was observations like this that led Davison to posit a "third-person effect": that people tend to believe media messages have greater effects on others than on themselves (the perceptual component), and that they act on this belief (the behavioral component). ${ }^{3}$

In the context of the third-person effect, Perloff ${ }^{4}$ has suggested that people hold a lay theory of media, or media schema, resembling the "hypodermic" model: "To the degree that individuals believe that the average person is susceptible to media or that the media are all-powerful, they can logically infer that others are more vulnerable to media than themselves." ${ }^{5}$ Media schemas also have been used to explain the third-person effect's "target corollary," how people's estimates of a group's exposure to a message predict their estimates of the message's effect on that group. ${ }^{6}$ In short, if people assume media are powerful, then exposure equals effects.

JEMC Quarterly Vol. 83, No. 3 Autumn 2006 632-649 (C2006 AEJMC 
However, there is to date only one empirical study of media schemas' role in third-person perceptions. ${ }^{7}$ Moreover, it would seem that media schemas about the power of the media and vulnerability of others to influence could not easily account for first-person perceptions, wherein others are seen as less influenced by desirable media messages than oneself. ${ }^{8}$ No one has yet investigated media schemas in the context of desirable messages, but Perloff suggested that there may be media schemas specific to socially desirable content that would contain beliefs about the relative weakness of positive messages and the intractability of the audience. ${ }^{9}$

Third- and first-person perceptions both deal with differences between perceived media effects on others versus on the self. Some recent research has advocated investigating not just differential but also joint perceived effects. ${ }^{10}$ No research has yet addressed how media schemas might be related to these "second-person perceptions" of mutual influence.

This study sets out to explore the beliefs audiences hold regarding the effects of anti-social and pro-social media content. A series of focus groups was conducted to determine those beliefs and how they were expressed. Focus group data aided the development of reliable quantitative measures of schemas to test their relationships with perceived media effects as well as third-, first-, and second-person perceptions.

Social psychology literature suggests people have multiple schemas for understanding and processing information, not all of which will be activated at any given time. Perceiver, situation, and stimulus characteristics affect what schemas are applied. ${ }^{11}$ In the case of estimating media effects, there are several relevant features: the topic of the media message, the desirability of the message, the receiver, and more. To make a judgment, presumably, people call upon schemas that include what they know and believe about each of these; they may also combine schemas and reason from them. ${ }^{12}$ But a schema that doesn't fit the stimulus or situation probably will not be applied.

The only study to date that empirically linked media schemas and perceived media effects was from Price and colleagues. ${ }^{13}$ They measured existing media schemas and found evidence that two schemas, "news media are powerful" and "people are vulnerable to media influence," were positively related to third-person perceptions (weakly) and perceptions of impact on others (somewhat more robustly).

McLeod, Eveland, and colleagues used the notion of a lay theory of hypodermic effects in their target corollary. ${ }^{14}$ They argued that people habitually draw cause-and-effect attributions about things they observe, so when they see a message that advocates a certain behavior and see that behavior displayed, they assume media messages are powerful. Consequently, people assume that exposure equals effects, and they infer effects of a message on a group from a group's perceived exposure. This research demonstrated that perceived exposure of a group was a consistent predictor of effects of some socially undesirable content.

\section{Media Schemas and Perceived Media Effects}


But do people consider all media messages to be equally powerful? What if people were aware of ongoing anti-social behavior despite a prevalent pro-social media message? It would be difficult to conclude that exposure equals effects, and indeed Meirick found the target corollary may not apply for desirable messages. ${ }^{15}$ Perceived exposure to prosocial messages was not related to perceived effects in sixteen of eighteen cases. That study identified one alternate explanation, the perceived attitudes of the groups toward the behavior in question, but it echoed Perloff in mentioning the possibility that different media schemas apply for pro-social messages. ${ }^{16}$

The English lexicon is full of idioms regarding the persistence of undesirable behaviors and the futility of attempts to change them: "You can't teach an old dog new tricks." "You can lead a horse to water, but you can't make it drink." "Old habits die hard." The widespread use of these idioms suggests there may exist lay theories about the uselessness of trying to change people. The extent to which people subscribe to such theories should be negatively related to the effects of desirable messages that they perceive on others. If these schemas are not applied to the self as they are to others, we would expect to see these beliefs positively related to first-person perceptions.

Differential Effects and Joint Effects
Third-person perception occurs when perceived media effects are greater for others than for oneself. The coinage comes from Davison's statement, "In the view of those trying to evaluate the effects of communication, its greatest impact will not be on 'me' or 'you,' but on 'them'the third persons." ${ }^{17}$ Conversely, when messages are considered "smart to be influenced by,"18 third-person perception can be muted or even reversed into first-person perception, in which the greatest impact is on "me." Neuwirth and colleagues recently called for broadening perceived effects research to include what they call second-person perception: a belief of mutual influence on the self and others. ${ }^{19}$ Here, media effects are not perceived to be on "me" or on "them" exclusively, but on "us."

Price and colleagues found media schemas of gullible audiences or powerful media are positively related to third-person perception mainly due to their influence on perceived effects on others, rather than effects on the self. ${ }^{20}$ This is consistent with evidence that people make estimates of media effects differently for themselves versus others, employing an exposure heuristic consistent with a powerful media schema for others but not themselves. ${ }^{21}$ This would suggest that media schemas would not predict second-person perception. On the other hand, perceptions of media effects on self and others tend to be positively correlated, even when they are significantly different. Moreover, the false consensus effect contends that people base their perceptions of others' opinions on their own. This makes the question of the relationship between media schemas and second-person perception an open one. 
Focus Groups. To develop measures of schemas people may have about desirable media messages, three focus group sessions $\left(N^{\prime} s\right.$ of 7,7 , and 8) were conducted with participants recruited from communication classes at a large Midwestern university. A semi-structured protocol was used to elicit responses. Sessions were digitally recorded, listened to repeatedly, and transcribed. Transcripts were then examined for common themes relevant to the perceived effects of pro-social messages. The following themes emerged:

Inertia, Habit, Resistance. Participants said people often do not want to change their behavior, that they will not change unless they truly want to, and that even when they do want to change, they may be unable to.

- People are going to do what they want to do.

- They don't want to be told what to do.

- If you're used to doing something for a very long time, sometimes it's impossible to not do it. It's second nature.

- You can try to help someone all you want. ... But until they make up their mind and say, "You know what, I want to quit for me," then you can't make them do it.

Avoidance of Effort or Negative Affect. Participants suggested that people tend to follow the path of least resistance and wish to avoid difficult tasks.

- Most people will do whatever's easiest for them.

- It's human nature to take the easiest way out and not work hard if you don't have to.

Participants also said people avoid unpleasant thoughts and feelings. As one put it, "You don't want to be bummed out." They suggested people's avoidance of negative affect could be why public service announcements (PSAs) are not effective.

- The commercials tell people they should be responsible, and you don't want to feel guilty about something, so you just like change the channel or something.

Invulnerability. Optimistic bias is the tendency of people to believe bad things are less likely to happen to them than other people. ${ }^{22}$ Although it is unlikely they have studied it, some participants articulated an awareness of this human tendency.

- We think of ourselves as untouchable sometimes. 
- Most people think, "It's not going to happen to me."

PSAs Are Not Cool. Several participants indicated they think PSAs discouraging tobacco, alcohol, and drug use are "cheesy," melodramatic, and unrealistic. Some said they have observed peers making fun of such messages.

- People will think those commercials are overdramatized.

- The ones I've seen are all kind of cheesy and dorky, so it gives them a bad connotation or whatever. I've seen the ones where a kid brings a six-pack to a party and they're all like, "Oh, not cool." I mean, that would never, ever, ever happen.

Exploratory Factor Analysis. Typically a description of the independent variables of a study would be contained in the methods section, but the exploratory nature of this study required determining these variables before positing appropriate hypotheses. Most of the themes found in the focus groups emerged as factors in the analysis.

Thirteen items based on the data from the focus groups and eight drawn from the work of Price and colleagues, ${ }^{23}$ all scored on a 0 (strongly disagree) to 8 (strongly agree) response scale, were used to measure beliefs about media and audiences. These twenty-one items were submitted to an exploratory factor analysis using principal components analysis and oblique rotation, which allows the resulting factors to be correlated. The first run identified seven factors, but one factor had only one item with a loading greater than .50 . Another item was not clearly associated with any single factor. These two items were dropped and the analysis rerun. Five factors were identified, with one item loading below .30 on all factors. This item was dropped and the analysis rerun. Table 1 shows the items comprising the resulting five factors and their standardized scale reliabilities.

With the independent variables created, appropriate hypotheses can be formulated.

Following the work of Price and colleagues, we would expect that beliefs in the power of the media will be positively associated with perceived effects of undesirable messages on others and with third-person perceptions. ${ }^{24}$ Price and colleagues also found that belief in the gullibility of audiences was a positive predictor of perceived effects of undesirable messages on others and of third-person perceptions. The relevant variable here is the savvy audience schema, essentially a reverse-coded version of their variable, so it would be appropriate to pose the opposite prediction.

H1: A belief in powerful media will be positively related with perceived effects of undesirable messages on others. 


\section{TABLE 1}

Factor Analysis and Reliabilities for Media Schemas

Schemas and Items Assigned to Them
Factors

$$
\begin{array}{lllll}
1 & 2 & 3 & 4 & 5
\end{array}
$$

Invulnerable Schema $(\alpha=.77)$

$\begin{array}{llllll}\text { When people are told about the risks of something they're doing, } & .80 & -.06 & -.03 & .41 & .21\end{array}$ they usually think, "It's not going to happen to me."

People think of themselves as indestructible.

For most people, public service announcements go in one ear and out the other.

People will do whatever's easiest for them.

Savvy Audience Schema $(\alpha=.67)$

Most people have the ability to judge the accuracy of what they see and hear.

Most people can figure out which media messages are in their best interests--and act on those messages.

Most people are smart enough to recognize what is believable and what is not.

Most people blindly accept things they hear about. (Reversed)

Laughable PSAs Schema $(\alpha=.76)$

Public service announcements are cheesy.

Public service announcements are overdramatic.

People make fun of public service announcements.

Powerful Media $(\alpha=.79)$

The media influence how people make decisions.

The media are very influential in our society.

The media don't really influence what most people think.

(Reversed)

Avoidance $(\alpha=.70)$

People don't want to watch things that make them feel bad about themselves

People avoid things that are depressing to think about.

You can't make people change unless they really want to.

Old habits are hard to break.

$\begin{array}{rrrrr}.77 & -.02 & -.16 & .30 & .33 \\ .78 & -.02 & .24 & -.11 & .22 \\ & & & & \\ .66 & -.06 & .17 & .12 & .47 \\ -.08 & .82 & -.13 & .00 & -.09 \\ & & & & \\ .02 & .79 & -.10 & -.07 & .04 \\ & & & & \\ .13 & .67 & -.18 & -.26 & -.02 \\ & & & & \\ -.20 & .54 & .04 & -.31 & -.31 \\ & & & & \\ -.05 & -.10 & .82 & .01 & .19 \\ .07 & -.08 & .82 & .01 & .07 \\ .15 & -.18 & .79 & .10 & .02 \\ & & & & \\ .22 & -.14 & .06 & .85 & .24 \\ .27 & -.11 & .04 & .89 & .22 \\ .04 & -.22 & .03 & .73 & .23 \\ & & & & \\ .30 & -.11 & .10 & .36 & .79 \\ .23 & .06 & .05 & .19 & .71 \\ .13 & -.19 & .08 & .06 & .72 \\ .38 & -.02 & .04 & .21 & .62\end{array}$

Note: $N=152$. Factor loadings are those reported in the structure matrix after oblique (SPSS oblimin) rotation. Cronbach's alphas for the scales were computed after standardizing the variables and reverse-coding the ones labeled as reversed.

H2: A belief in savvy audiences will be negatively related with perceived effects of undesirable messages on others.

H3: A belief in powerful media will be positively related with third-person perception for undesirable messages.

H4: A belief in savvy audiences will be negatively related with third-person perception for undesirable messages.

Perloff opined that schemas about the effects of pro-social media messages, involving beliefs in the weakness of these messages and people's resistance to positive change, would lead to smaller perceived 
effects of these messages on others. ${ }^{25}$ To the extent that these schemas are applied to effects estimates for others and not for the self, we would expect them to be positively associated with first-person perceptions for these messages. The applicable independent variables here are the laughable PSA, invulnerable, and avoidance schemas.

H5: A belief that PSAs are laughable will be negatively related with perceived effects of desirable messages on others.

H6: A belief that people see themselves as invulnerable will be negatively related with perceived effects of desirable messages on others.

H7: A belief that people want to avoid negative affect and change will be negatively related with perceived effects of desirable messages on others.

H8: A belief that PSAs are laughable will be positively related with first-person perception for desirable messages.

H9: A belief that people see themselves as invulnerable will be positively related with first-person perception for desirable messages.

H10: A belief that people want to avoid negative affect and change will be positively related with first-person perception for desirable messages.

Price and colleagues found no relationship between media schemas and perceived effects of messages on the self. ${ }^{26}$ We would not expect to find such a relationship if schemas about media influence are arrived at, as Eveland and colleagues suggest, from observation of others' behaviors. ${ }^{27}$ But if these schemas are derived from observing oneself, that would be a different story.

RQ1: What is the relationship between media schemas and perceived media effects on oneself?

The question of the extent to which media schemas are applied to the self bears on another question: whether they are related to secondperson perceptions of joint media influence.

RQ2: What is the relationship between media schemas and second-person perceptions?

Subjects and Design. Data were gathered from a convenience sample of 152 undergraduates at a large Midwestern university who took part in exchange for credit in communication classes. Fifty-eight percent of the respondents were female. The mean age was 20.2 years $(s d=1.62)$, 
and $22.5 \%$ identified themselves as members of racial or ethnic minorities. The study was administered via paper-and-pencil questionnaire. In that each respondent was asked about four kinds of media content, this study employed a repeated-measures design. Two kinds of content, cigarette and alcohol advertisements, are generally deemed in the literature to be undesirable. The other two, anti-tobacco ads and anti-drunk-driving PSAs, are generally deemed desirable.

Dependent Measures. The independent variables, the media schemas, were described earlier. The following paragraphs describe the dependent variables. Responses were typically on a scale of 0 to 8 and bipolar when appropriate.

Perceived Effects on Self and Others. Four sets of effects questions were asked, one set for each kind of media content. Respondents were asked, "How do you think (type of content) affects the likelihood that the following people will (smoke/drink/drive drunk)?" Each question was asked for "you" and for three comparison groups ("your friends," "U students," and "the public in general").

Third-, First-, and Second-Person Perceptions. Third-person perceptions are operationalized as the perceived effects of a message on a group minus the perceived effect on the self. First-person perceptions are perceived effects on the self minus effects on a group. Second-person perceptions are the sum of perceived effects of a message on the self and on a group.

Control Variables. For a more stringent test of the relationship of media schemas to perceived media effects and person perceptions, a number of control variables were measured:

Perceived Similarity. This variable taps social distance, one explanation for perceived effects on others such that as distance increases, perceived effects of messages become more different from perceived effects on the self. ${ }^{28}$ Two items were used to assess respondents' feelings of similarity to and identification with the comparison groups. For each group, the similarity and identification ratings were summed to create a twoitem scale. Correlations between the two items were .48 for the public, .49 for other students, and .67 for friends.

Perceived Exposure. The target corollary offers this as a predictor of perceived effects on others such that as exposure increases, perceived effects increase. For each of the messages and groups, subjects were asked, "How often do you think the following people see (type of content)?"

Perceived Predispositions. Perceived predispositions of groups to the behaviors advocated or discouraged in media messages can predict perceived media effects. ${ }^{29}$ One's own predisposition to the behavior can serve not only as a predictor of perceived effects on the self, but also an indicator of the desirability of the message and a control variable in every model. For all message topics and comparison groups, subjects were asked, "How would you describe the following people's attitudes toward (drinking/smoking/driving drunk)?"

One's Behavior. Participants were asked about how frequently they smoke, drink, or have driven when they probably would have failed a 
breathalyzer test. Alcohol use also was measured with an additional question, "When you drink, how much do you usually drink?" The two alcohol use items were standardized and summed to create a scale $(r=$ .69; standardized alpha $=.82$ ).

Data Analysis. The following analyses used the control variables and the five media schema measures as predictors in a series of multiple regressions. In the interests of brevity, analyses for comparison groups other than students are not presented here, but are available from the author; the results are comparable. In each regression, a demographic controls block (gender, age, own predisposition, and own behavior) was entered first. Next came a block of known predictors (perceived similarity, perceived exposure, and perceived predisposition). Finally the media schemas were entered.

In models predicting the differential effects of first- or third-person perception, the joint effects (second-person perception) were used as a control following the logic of a diamond regression model. ${ }^{30}$ Conversely, in models predicting second-person perception, differential effects were entered as a control variable. This approach is not a diamond model per se, in which both the sum and difference score of two variables are entered as predictors. But these analyses do employ the logic of the diamond model in that they control for the influence of the difference of two variables on their sum, and vice versa, for a more conservative test of the relationship between the main variables of interest-the media schemas-and person perceptions. ${ }^{31}$

First- and Third-Person Perceptions. As a preliminary step, a series of paired-samples $t$-tests were run to detect the presence of firstand third-person perceptions (see Table 2). As expected, third-person perceptions were evident for cigarette and alcohol advertising. Conversely, there were significant first-person perceptions for anti-tobacco ads and anti-drunk-driving PSAs.

Media Schemas and Perceived Effects of Undesirable Messages. It was predicted that a belief in powerful media (H1) would be positively related with perceived effects of undesirable messages on others, while a belief in savvy audiences (H2) was expected to be negatively related to perceived effects on others (see Table 3). The powerful media schema was not significantly related to perceived effects on other students for either message, so $\mathbf{H 1}$ is not supported. Belief in savvy audiences was not related to perceived effects of either message on students, so $\mathbf{H} 2$ is also not supported.

Media Schemas and Third-Person Perception. H3 predicted that belief in a powerful media would be positively related to third-person perception, while $\mathrm{H} 4$ predicted that belief in savvy audiences would be negatively related. As Table 3 shows, neither hypothesis received any support. None of the five media schemas was significantly related to third-person perception for either message.

Media Schemas and Perceived Effects of Desirable Messages. It was predicted that the beliefs that PSAs are laughable (H5), that people see themselves as invulnerable (H6), and that people want to avoid neg- 
TABLE 2

Perceived Media Effects on Self and Others

\begin{tabular}{|c|c|c|c|c|c|c|c|}
\hline \multirow[t]{2}{*}{ Message Type } & Self & \multicolumn{2}{|c|}{ Friends } & \multicolumn{2}{|c|}{ Other Students } & \multicolumn{2}{|c|}{ Public } \\
\hline & $M \quad(\mathrm{sd})$ & $M$ & (sd) & $M$ & (sd) & $M$ & (sd) \\
\hline Cigarette Advertising & $2.93(1.95)$ & $3.64^{\star \star \star}$ & (1.74) & $4.46^{\star * *}$ & (1.45) & $5.40^{\star \star \star}$ & (1.15) \\
\hline Alcohol Advertising & $4.57(1.63)$ & $5.18^{\star \star *}$ & (1.48) & $6.10^{\star * *}$ & (1.19) & $6.02^{* \star \star}$ & $(1.20)$ \\
\hline Anti-tobacco Ads & $5.74(1.88)$ & $5.19^{\star \star \star}$ & (1.56) & $4.55^{\star \star \star}$ & $(1.25)$ & $4.47^{\star \star \star}$ & (1.28) \\
\hline Anti-drunk-driving PSAs & $5.80(1.89)$ & $5.22^{\star \star *}$ & (1.76) & $4.46^{\star \star \star}$ & (1.43) & $4.49^{\star \star \star}$ & (1.46) \\
\hline
\end{tabular}

Note: $N=151$ or 152 . Means are on a 0 -to-8 scale (midpoint of 4 ), with higher values indicating greater persuasion. Values for others that are significantly different from values for the self are indicated with asterisks.

$\wedge p<.10 ;{ }^{*} p<.05 ;{ }^{* \star} p<.01 ;{ }^{* \star *} p<.001$

ative affect and change (H7) would be negatively related to perceived effects of desirable messages on others (see Table 4). The laughable PSA schema had a significant negative relationship with perceived effects of anti-tobacco ads on other students, while its negative relationship with effects of drunk-driving PSAs on other students approached significance. $\mathrm{H} 5$ receives some support. The invulnerable schema likewise had one significant negative beta and another approaching significance, so $\mathrm{H6}$ also receives some support. But the avoidance schema did not relate to perceived effects of desirable messages, so H7 is not supported.

Media Schemas and First-Person Perception. It was predicted that belief in three schemas relevant to estimating effects of pro-social messages would be positively related to first-person perception: beliefs that PSAs are laughable (H8), that people see themselves as invulnerable (H9), and that people want to avoid negative affect and change (H10). Table 4 shows no significant relationships for the laughable PSAs schema or the avoidance schema, so $\mathbf{H 8}$ and $\mathbf{H 1 0}$ are not supported. The belief that people are invulnerable was positively related to perceiving the self as more affected by anti-tobacco ads than other students, a relationship that approached significance. $\mathbf{H} 9$ receives very limited support.

Media Schemas and Perceived Effects on Oneself. The columns labeled "self" in Tables 3 and 4 shed some light on the research question. Despite previous work suggesting that media schemas are not related to perceived effects on the self, at least one schema showed such a relationship for each of the four messages. The powerful media schema was positively related to perceived effects of cigarette ads on the self. The avoidance schema was negatively related to perceived effects of alcohol ads on the self, such that the more participants thought people avoid change and feeling bad, the less they thought alcohol ads influenced themselves. The savvy audience schema was positively associated with perceived effects of drunk-driving PSAs; the more savvy they thought people were, 
TABLE 3

Predictors of Perceived Effects of Undesirable Messages

\begin{tabular}{|c|c|c|c|c|c|c|}
\hline \multirow[b]{2}{*}{ Predictor } & \multicolumn{3}{|c|}{ Cigarette Ads } & \multicolumn{3}{|c|}{ Alcohol Ads } \\
\hline & Self & $\begin{array}{c}\text { Other } \\
\text { Students }\end{array}$ & $\begin{array}{l}\text { Others Minus } \\
\text { Self }\end{array}$ & Self & $\begin{array}{l}\text { Other } \\
\text { Students }\end{array}$ & $\begin{array}{c}\text { Others Minus } \\
\text { Self }\end{array}$ \\
\hline Joint Effects & $\ldots$ & $\ldots$ & $-.25^{* \star}$ & $\ldots$ & $\ldots$ & $-.18^{*}$ \\
\hline Block $R^{2} \Delta$ & $\ldots$ & $\ldots$ & $.10^{\star \star \star}$ & $\ldots$ & $\ldots$ & $.08^{\star \star \star}$ \\
\hline Gender (Female) & -.04 & .05 & .05 & -.01 & -.09 & -.03 \\
\hline Age & .04 & -.17 & $-.18^{*}$ & -.02 & .05 & .06 \\
\hline Own Predisposition & $.20^{\wedge}$ & .01 & $-.18^{\wedge}$ & $.50^{\star \star \star}$ & .04 & $-.36^{\star \star}$ \\
\hline Own Behavior & $.17^{\wedge}$ & -.02 & -.16 & .08 & -.12 & $-.21^{\wedge}$ \\
\hline Block $R^{2} \Delta$ & $.16^{\star \star \star}$ & .05 & $.19^{\star \star \star}$ & $.36^{\star \star \star}$ & .03 & $.30^{\star * \star}$ \\
\hline Perceived Similarity & $\ldots$ & .11 & .05 & $\ldots$ & -.05 & -.07 \\
\hline Perceived Predisposition & $\ldots$ & .10 & .10 & $\ldots$ & $.34^{\star \star *}$ & $.17^{*}$ \\
\hline Perceived Exposure & .06 & .11 & .12 & $.24^{* * *}$ & $.33^{\star \star \star}$ & .07 \\
\hline Block $R^{2} \Delta$ & .01 & $.05^{\wedge}$ & .03 & $.04^{* *}$ & $.26^{\star \star *}$ & $.05^{\star \star}$ \\
\hline Invulnerable Schema & .10 & .03 & .10 & -.04 & -.06 & -.02 \\
\hline Savvy Audience Schema & .08 & .06 & -.02 & -.08 & -.09 & -.03 \\
\hline Laughable PSAs Schema & $.17^{\star}$ & .12 & -.04 & .00 & .01 & .04 \\
\hline Powerful Media Schema & $16^{*}$ & .13 & -.03 & .02 & -.04 & -.04 \\
\hline Avoidance Schema & -.05 & -.10 & -.05 & $-.14^{*}$ & -.09 & .07 \\
\hline Block $R^{2} \Delta$ & $.06^{\wedge}$ & .03 & .01 & .03 & .02 & .01 \\
\hline$R^{2}$ & $.22^{\star \star \star}$ & $.13^{\wedge}$ & $.32^{\star \star \star}$ & $.44^{* \star *}$ & $.31^{\star \star \star}$ & $.44^{\star \star \star}$ \\
\hline$N$ & 150 & 150 & 150 & 148 & 148 & 148 \\
\hline
\end{tabular}

Note: Coefficients reported are standardized final betas. Positive coefficients indicate that a higher score on the schema is associated with greater perceived effects of the undesirable messages (greater likelihood to smoke or drink) on the group.

$\wedge p<.10 ;{ }^{*} p<.05 ;{ }^{* *} p<.01 ;{ }^{* * *} p<.001$

the more they thought the PSAs would affect themselves. The laughable PSAs schema was negatively related to perceived effects of anti-tobacco ads on the self and positively related to perceived effects of cigarette ads on the self.

Media Schemas and Second-Person Perception. Table 5 addresses the second research question, the relationships between media schemas and second-person perception:

Invulnerable Schema. This belief that people see themselves as invulnerable was negatively related to perceived mutual effects of drunk-driving PSAs on the self and other students.

Savvy Audiences Schema. A belief in savvy audiences was negatively related to second-person perception for anti-tobacco ads.

Laughable PSAs Schema. A belief that PSAs are laughable was negatively associated with second-person perceptions for anti-tobacco ads and (marginally) for drunk-driving PSAs. This schema also had a marginally significant positive association with the perceived mutual effects of cigarette ads.

Powerful Media Schema. A belief that the media influence our decisions and our society had a marginally significant positive association with second-person perceptions for cigarette. 
TABLE 4

Predictors of Perceived Effects of Desirable Messages

\begin{tabular}{|c|c|c|c|c|c|c|}
\hline \multirow[b]{2}{*}{ Predictor } & \multicolumn{3}{|c|}{ Anti-tobacco Ads } & \multicolumn{3}{|c|}{ Drunk-driving PSAs } \\
\hline & Self & $\begin{array}{c}\text { Other } \\
\text { Students }\end{array}$ & $\begin{array}{c}\text { Others Minus } \\
\text { Self }\end{array}$ & Self & $\begin{array}{l}\text { Other } \\
\text { Students }\end{array}$ & $\begin{array}{c}\text { Others Minus } \\
\text { Self }\end{array}$ \\
\hline Joint Effects & $\ldots$ & $\ldots$ & $.29^{\star \star \star}$ & $\ldots$ & $\ldots$ & $.31^{\star \star \star}$ \\
\hline Block $R^{2} \Delta$ & $\ldots$ & $\ldots$ & $.15^{* \star \star}$ & $\ldots$ & $\ldots$ & $.09^{* \star *}$ \\
\hline Gender (Female) & .08 & .01 & .04 & .08 & .00 & .04 \\
\hline Age & -.04 & .04 & -.05 & $-.19^{\star}$ & $-.23^{\star \star}$ & .05 \\
\hline Own Predisposition & $-.44^{\star \star \star}$ & -.15 & $-.20^{\star}$ & $-.33^{\star \star}$ & -.02 & $-.28^{\star \star}$ \\
\hline Own Behavior & -.04 & .13 & -.11 & .00 & $-.19^{*}$ & $-.14^{\wedge}$ \\
\hline Block $R^{2} \Delta$ & $.29^{\star \star \star}$ & .04 & $.14^{\star * *}$ & $.20^{\star \star \star}$ & $.11^{\star \star}$ & $.09^{* *}$ \\
\hline Perceived Similarity & $\ldots$ & .03 & -.02 & $\ldots$ & -.03 & -.02 \\
\hline Perceived Predisposition & $\ldots$ & $-.27^{\star \star}$ & $.26^{\star \star \star}$ & $\ldots$ & $-.38^{\star \star \star}$ & $.43^{\star \star \star}$ \\
\hline Perceived Exposure & .01 & $.22^{* *}$ & $-.16^{*}$ & .12 & .01 & .06 \\
\hline Block $R^{2} \Delta$ & .00 & $.13^{\star \star \star}$ & $.09^{\star \star \star \star}$ & .01 & $.13^{\star * *}$ & $.16^{* \star \star}$ \\
\hline Invulnerable Schema & .04 & $-.16^{\wedge}$ & $.15^{\wedge}$ & -.04 & $-.19^{\star}$ & .12 \\
\hline Savvy Audience Schema & .10 & $-.15^{*}$ & .04 & $.17^{*}$ & .03 & .11 \\
\hline Laughable PSAs Schema & $-.30^{* \star *}$ & $-.21^{*}$ & -.05 & -.07 & $-.14^{\wedge}$ & .06 \\
\hline Powerful Media Schema & -.11 & -.03 & -.06 & .05 & .07 & -.02 \\
\hline Avoidance Schema & -.03 & .00 & -.02 & .07 & .08 & -.03 \\
\hline Block $R^{2} \Delta$ & $.10^{\star \star}$ & $.08^{\star}$ & .02 & .04 & $.05^{\wedge}$ & .03 \\
\hline$R^{2}$ & $.39^{* * *}$ & $.25^{\star * \star}$ & $.41^{\star \star \star}$ & $.25^{\star \star *}$ & $.28^{* \star *}$ & $.36^{\star * \star}$ \\
\hline$N$ & 149 & 150 & 149 & 150 & 150 & 150 \\
\hline
\end{tabular}

Note: Coefficients reported are standardized final betas. Positive coefficients indicate that a higher score on the schema is associated with greater perceived effects of the desirable messages (smaller likelihood to smoke or drive drunk) on the group.

$\wedge p<.10 ; \bullet p<.05 ;{ }^{\star \star} p<.01 ;^{\star \star \star} p<.001$

Avoidance Schema. A belief that people want to avoid change and negative emotions was negatively associated with perceptions of joint impact of alcohol ads.

Before considering the hypotheses, let us discuss the control variDiscussion ables. First, consistent with other findings, perceived similarity showed no significant relationships with any dependent variables..$^{32}$ Second, perceived predispositions were consistently related to perceived effects on self and others, which previous research had shown, ${ }^{33}$ as well as to first-, second-, and third-person effects, which had not yet been tested. Third, perceived exposure predicted perceived effects of anti-tobacco ads, the first time such a relationship has been shown for a desirable message. This finding suggests lay theories of hypodermic media effects may sometimes extend to pro-social messages and foreshadows some of the complexity to come in the discussion.

As for the hypotheses, this study contains several surprising results, not the least of which were the null ones. It had been predicted that beliefs in a powerful media and a savvy audience would be related (positively and negatively, respectively) to perceived effects of undesir- 
TABLE 5

Predictors of Second-Person Perceptions, Self + Other Students

Undesirable Messages

Desirable Messages

Predictor

Cigarette Ads Alcohol Ads

Anti-tobacco Ads Drunk-driving PSAs

\begin{tabular}{|c|c|c|c|c|}
\hline Differential Effects & $-.29^{* \star}$ & $-.19^{*}$ & $.30^{\star \star \star}$ & $.32^{\star \star \star}$ \\
\hline Block $R^{2} \Delta$ & $.10^{\star \star \star}$ & $.09^{\star \star \star}$ & $.15^{\star \star \star}$ & $.09^{\star \star \star}$ \\
\hline Gender (Female) & .03 & -.08 & .04 & .02 \\
\hline Age & -.10 & .02 & .02 & $-.26^{* * *}$ \\
\hline Own Predisposition & .10 & $.28^{*}$ & $-.34^{\star \star \star}$ & $-.18^{\wedge}$ \\
\hline Own Behavior & .05 & .00 & .08 & $.16^{\wedge}$ \\
\hline Block $R^{2} \Delta$ & $.03^{\star}$ & $.09^{\star *}$ & $.09^{\star *}$ & $.15^{\star \star \star}$ \\
\hline Perceived Similarity & 10 & -.01 & .03 & -.05 \\
\hline Perceived Predisposition & .06 & $.29^{\star \star \star}$ & $-.15^{\wedge}$ & $-.23^{\star \star}$ \\
\hline Perceived Exposure & .07 & $.35^{\star \star \star}$ & $.15^{\star}$ & .05 \\
\hline Block $R^{2} \Delta$ & .03 & $.20^{\star * *}$ & $.05^{\star}$ & $.04^{\star}$ \\
\hline Invulnerable Schema & -.02 & -.06 & -.09 & $-.16^{*}$ \\
\hline Savvy Audience Schema & .07 & -.08 & $-.16^{*}$ & .09 \\
\hline Laughable PSAs Schema & $.16^{\wedge}$ & -.02 & $-.30^{\star \star \star}$ & $-.14^{\wedge}$ \\
\hline Powerful Media Schema & $.16^{\wedge}$ & -.02 & -.08 & .08 \\
\hline Avoidance Schema & -.09 & $-.15^{*}$ & -.01 & .09 \\
\hline Block $R^{2} \Delta$ & .05 & .04 & $.11^{\star \star \star}$ & $.05^{\wedge}$ \\
\hline$R^{2}$ & $.21^{\star \star}$ & $.41^{\star \star \star}$ & $.40^{\star \star \star}$ & $.33^{\star \star \star}$ \\
\hline$N$ & 150 & 148 & 149 & 150 \\
\hline
\end{tabular}

Note: Coefficients reported are final standardized betas. Positive coefficients indicate that a higher score on the schema is associated with greater perceived effects on both the self and others. Differential effects are third-person perceptions for undesirable messages and first-person perceptions for desirable messages.

$\wedge p<.10 ;{ }^{\star} p<.05 ;{ }^{\star *} p<.01 ;{ }^{\star \star \star} p<.001$

able messages on others, but these predictions received little support. Price and colleagues had found the powerful media schema related to perceived effects of pornography news on others, while a belief that people are vulnerable to media influence was related to perceived effects on others of two other news stories. The current research included several controls Price and colleagues did not, but rerunning the regressions here without the control blocks did not substantially change the results. A more likely explanation for the weaker results may be a combination of different messages and a smaller $N$ here; the latter is a limitation of note.

This study created measures for three schemas that were expected to be negatively related to perceived effects of pro-social media messages. There was some support for two of these performing as expected. The laughable PSAs and invulnerable schemas each had negative coefficients that reached or approached significance in the regressions predicting effects on others. Price and colleagues had not found media schemas to be related to perceived effects on the self, but there were some instances of that here. Only five out of the twenty coefficients 
were significant, but four of the five schemas were related with perceived effects on the self at least once.

These hypotheses assumed, as Perloff did, that a given media schema would influence either pro-social or anti-social messages, not both. ${ }^{34}$ This was not necessarily the case. People seemed able to apply media schemas selectively, so that at times signs changed in moving from anti-social to pro-social messages, or from self to others. A belief in savvy audiences was positively related to perceived effects of a pro-social message on the self, yet negatively related to the perceived effects of a different pro-social message on other students. In the first message, it seems participants associated the savvy audience schema with the self; in the next, they pointedly disassociated it from other students. In the case of the belief that PSAs are laughable, the schema was negatively associated with perceived effects of anti-tobacco messages (on the self and other students), as if this belief suppressed perceived effects of the pro-social message.

This same schema was positively related to perceived effects of cigarette ads on the self, such that the cheesier you thought PSAs were, the more influenced you thought you would be by cigarette ads. The applicability of this schema may be related to the fact that anti-tobacco ads often make tobacco ads themselves their main target, or because PSAs are the antithesis of the much more appealing images purveyed elsewhere. As one focus group participant put it:

- They never show anything cool, they never show anybody having fun, they never show anything great or hip about it. It's always kind of a sobering moment. The rest of media is so full of like, car chases and funny beer commercials, friends, you know.

Clearly, these schemas contain sometimes contradictory beliefs about people and about media. Zaller and Feldman explored the notion of conflicting considerations and the ways in which the considerations called to mind by a question's wording could affect survey responses. ${ }^{35}$ Their findings suggest that the schema or schemas applied and activated to make a judgment might have consequences for the media effects estimate one arrives at. Conceivably a media effects question could be framed in such a way to make a given media schema more or less salient. Of course, media content may prime certain schema as well. Individual PSAs that viewers encounter likely vary in their level of perceived laughability, affecting the applicability of a laughable PSAs schema. Likewise, messages may include references to the savvy or the avoidance tendencies of others. Manipulating questions or stimuli in future studies could add some causal direction to media schemas research, as well as help test the schemas approach.

The results for the relationships between media schemas and firstand third-person perceptions were remarkably weak, even weaker than the "somewhat disappointing" results of Price and colleagues, who had two results out of six significant at $p<.10 .^{36}$ Only one coefficient out of 
twenty even approached significance, the number we would have expected to find just by chance at an alpha level of .05.

By contrast, there was evidence that media schemas were related to second-person perception: seven significant or marginally significant coefficients out of twenty. This is a significantly greater proportion than was found for first- and third-person perception (Yates-corrected $\chi^{2}=$ $3.91, \mathrm{df}=1, p<.05$ ). It appears media schemas are better suited to predicting mutual effects than differential effects. This, combined with the fact that media schemas did in some cases relate to perceived effects on the self, suggests media schemas may be applied in estimating effects on self and others alike, typically in a similar direction. And while the laughable PSA schema predicted second-person perceptions for both desirable and undesirable messages, the other schemas did so only for one or the other, but not in a way that was suggested by the a priori division used in the hypotheses between undesirable and desirable message schemas. The invulnerable and savvy audience schemas were associated with second-person perceptions for the desirable messages only; the powerful media and avoidance schemas with such perceptions for the undesirable messages only. There were only two messages of each type, so further research is required before we can generalize about this seeming divide.

Another limitation is that message desirability was not directly assessed in this study, nor for that matter in much first- and third-person research. A priori assumptions of desirability here were based on message genre (PSA vs. product advertising) and previous pretests from other samples. One's own predisposition toward behavior advocated or discouraged in the message was used as a control, but this may not completely capture the notion of whether or not a message is "smart to be influenced by." 37

Among this study's other limitations is a small convenience sample of students, which limits generalizability and power. Also, the schemas presented here are not exhaustive. There are almost certainly other media schemas that people may use in estimating media effects on themselves and others. But the work here represents a long-delayed second step in further exploring the existence and impact of these belief structures.

\section{NOTES}

1. See Judith S. Trent and Robert V. Friedenberg, Political Campaign Communication: Principles and Practices, 4th ed. (Westport, CT: Praeger, 2000), 112-13, for a history of belief in the power of the press.

2. W. Phillips Davison, "The Third-Person Effect in Communication," Public Opinion Quarterly 47 (spring 1983): 1-15.

3. Davison, "The Third-Person Effect"; Jacob Cohen, Diana Mutz, Vincent Price, and Albert Gunther, "Perceived Impact of Defamation: An Experiment on Third Person Effects," Public Opinion Quarterly 52 (summer 1988): 161-73; Albert C. Gunther, "What We Think Others 
Think: Cause and Consequence in the Third Person Effect," Communication Research 18 (June 1991): 355-72; Dianne Rucinski and Charles T. Salmon, "The 'Other' as the Vulnerable Voter: A Study of the ThirdPerson Effect in the 1988 Campaign," International Journal of Public Opinion Research 2 (winter 1990): 345-68; Dhavan V. Shah, Ronald J. Faber, and Seounmi Youn, "Susceptibility and Severity: Perceptual Dimensions Underlying the Third-Person Effect," Communication Research 26 (April 1999): 240-67; Margaret E. Thompson, Stephen H. Chaffee, and Hayg H. Oshagan, "Regulating Pornography: A Public Dilemma," Journal of Communication 40 (summer 1990): 73-83.

4. Richard M. Perloff, "Third-Person Effect Research 1983-1992: A Review and Synthesis," International Journal of Public Opinion Research 5 (summer 1993): 167-84; Richard M. Perloff, "The Third-Person Effect: A Critical Review and Synthesis," Media Psychology 1 (winter 1999): 353-78.

5. Perloff, "The Third-Person Effect," 362.

6. William P. Eveland, Amy I. Nathanson, Benjamin H. Detenber, and Douglas M. McLeod, "Rethinking the Social Distance Corollary: Perceived Likelihood of Exposure and the Third-Person Perception," Communication Research 26 (June 1999): 275-302; Douglas M. McLeod, Benjamin H. Detenber, and William P. Eveland, "Behind the ThirdPerson Effect: Differentiating Perceptual Processes for Self and Other," Journal of Communication 51 (December 2001): 678-95.

7. Vincent Price, Li-Ning Huang, and David Tewksbury, "ThirdPerson Effects of News Coverage: Orientations toward Media," Journalism \& Mass Communication Quarterly 74 (autumn 1997): 525-40.

8. John R. Chapin, "Not Like Me: Self vs. Other Distinctions in FirstPerson Perception," Communication Research Reports 17 (summer 2000): 320-30; J.M. Innes and H. Zeitz, "The Public's View of the Impact of the Mass Media: A Test of the 'Third Person' Effect," European Journal of Social Psychology 18 (October-November 1988): 457-63; Albert C. Gunther and Esther Thorson, "Perceived Persuasive Effects of Product Commercials and Public Service Announcements: Third-Person Effects in New Domains," Communication Research 18 (October 1992): 355-72; Vera Hoorens and Suzanne Ruiter, "The Optimal Impact Phenomenon: Beyond the Third Person Effect," European Journal of Social Psychology 26 (July-August 1996): 599-610; H. Allen White, "Considering Interacting Factors in the Third-Person Effect: Argument Strength and Social Distance," Journalism \& Mass Communication Quarterly 74 (autumn 1997): 557-64; H. Allen White and John F. Dillon, "Knowledge About Others' Reaction to a Public Service Announcement: The Impact of SelfPersuasion and Third-Person Perception," Journalism \& Mass Communication Quarterly 77 (winter 2000): 788-803.

9. Perloff, "The Third-Person Effect."

10. Kurt Neuwirth and Edward Frederick, "Extending the Framework of Third, First, and Second-Person Effects," Mass Communication $\mathcal{E}$ Society 5 (spring 2002): 113-40; Kurt Neuwirth, Edward Frederick, and Charles Mayo, "Person-Effects and Heuristic-Systematic Processing," Communication Research 29 (June 2002): 321-60.

11. E. Tory Higgins, "Knowledge Activation: Accessibility, Appli- 
cability, and Salience," in Social Psychology: Handbook of Basic Principles, ed. E. Tory Higgins and Arie W. Kruglanksi (New York: Guilford Press, 1996), 133-68.

12. Ziva Kunda, Social Cognition: Making Sense of People (Cambridge, MA: MIT Press, 1999).

13. Price, Huang, and Tewksbury, "Third-Person Effects of News Coverage."

14. Eveland et al., "Rethinking the Social Distance Corollary"; McLeod, Detenber, and Eveland, "Behind the Third-Person Effect"; Douglas M. McLeod, William P. Eveland, and Amy I. Nathanson, "Support for Censorship of Violent and Misogynic Rap Lyrics: An Analysis of the Third-Person Effect," Communication Research 24 (April 1997): 153-74.

15. Patrick C. Meirick, "Rethinking the Target Corollary: The Effects of Social Distance, Perceived Exposure and Perceived Predispositions on First- and Third-Person Perceptions" Communication Research 32 (December 2005): 822-43.

16. Perloff, "The Third-Person Effect."

17. Davison, "The Third-Person Effect," 3.

18. Albert C. Gunther and Paul Mundy, "Biased Optimism and the Third-Person Effect," Journalism Quarterly 70 (spring 1993): 58-67.

19. Neuwirth and Frederick, "Extending the Framework." Grammarians might insist on renaming this "first-person-plural perception," but it would be unnecessarily awkward.

20. Price, Huang, and Tewksbury, "Third-Person Effects of News Coverage."

21. McLeod, Detenber, and Eveland, "Behind the Third-Person Effect."

22. Neil D. Weinstein, "Optimistic Biases About Personal Risks," Science, December 8, 1989, 1232-33.

23. Price, Huang, and Tewksbury, "Third-Person Effects of News Coverage."

24. Price, Huang, and Tewksbury, "Third-Person Effects of News Coverage."

25. Perloff, "The Third-Person Effect."

26. Price, Huang, and Tewksbury, "Third-Person Effects of News Coverage."

27. Eveland et al., "Rethinking the Social Distance Corollary."

28. Cohen et al., "Perceived Impact of Defamation"; Peter Gibbon and Kevin Durkin, "The Third Person Effect: Social Distance and Perceived Media Bias," European Journal of Social Psychology 25 (September-October 1995): 597-602; Gunther, "What We Think Others Think"; White, "Considering Interacting Factors."

29. Meirick, "Rethinking the Target Corollary."

30. Neuwirth and Frederick, "Extending the Framework." The diamond model is put forward in Hugh P. Whitt, "Status Inconsistency: A Body of Negative Evidence or a Statistical Artifact?" Social Forces 62 (September 1983): 201-33. Others using this model in the context of perceived media effects include McLeod, Detenber, and Eveland, "Behind 
the Third-Person Effect," and Shah, Faber, and Youn, "Susceptibility and Severity."

31. For other examples in which a summed or difference score is used as a dependent variable and its opposite is a control, see Neuwirth, Frederick, and Mayo, "Person-Effects and Heuristic-Systematic Processing" and Peter R. Giancola, "Influence of Subjective Intoxication, Breath Alcohol Concentration, and Expectancies on the AlcoholAggression Relation," Alcoholism: Clinical and Experimental Research 30 (May 2006): 844-50.

32. Eveland et al., "Rethinking the Social Distance Corollary"; McLeod, Eveland, and Nathanson, "Support for Censorship"; Meirick, "Rethinking the Target Corollary."

33. Meirick, "Rethinking the Target Corollary."

34. Perloff, "The Third-Person Effect."

35. John Zaller and Stanley Feldman, "A Simple Theory of the Survey Response: Answering Questions versus Revealing Preferences," American Journal of Political Science 36 (August 1992): 579-616.

36. Price, Huang, and Tewksbury, "Third-Person Effects of News Coverage," 535.

37. Gunther and Mundy, "Biased Optimism," 61. 